Revue Revue de l'histoire des religions

del'histoire des religions

2| 2015

Les images miraculeuses de la Vierge au premier âge moderne entre dévotion locale et culte universel

\title{
Les images miraculeuses de la Vierge au premier âge moderne, entre dévotion locale et culte universel
}

Avant-propos

Ralph Dekoninck

\section{OpenEdition}

Journals

Édition électronique

URL : http://journals.openedition.org/rhr/8391

DOI : 10.4000/rhr.8391

ISSN : 2105-2573

Éditeur

Armand Colin

Édition imprimée

Date de publication : 1 juin 2015

Pagination : 131-133

ISBN : 978-2-200-92965-7

ISSN : 0035-1423

Référence électronique

Ralph Dekoninck, "Les images miraculeuses de la Vierge au premier âge moderne, entre dévotion locale et culte universel », Revue de l'histoire des religions [En ligne], 2 | 2015, mis en ligne le 01 juin 2018, consulté le 25 septembre 2020. URL : http://journals.openedition.org/rhr/8391 ; DOI : https:// doi.org/10.4000/rhr.8391 


\title{
Les images miraculeuses de la Vierge au premier âge moderne, entre dévotion locale et culte universel
}

\author{
Avant-propos
}

L'objectif de ce numéro thématique est d'apporter un nouvel éclairage sur une culture visuelle et religieuse inscrite au confluent de deux temps que l'on a eu trop souvent tendance à opposer: l'ère de l'image et l'ère de l'art, la seconde ayant supposément supplanté la première. Et lorsqu'il est question de souligner la survivance de la première au cœur de la seconde, c'est bien souvent pour continuer à opposer culture laïque de l'art et culte religieux de l'image. Or c'est oublier que ce dernier, au-delà des continuités avec le Moyen Âge, connaît de profondes mutations, attestant d'une imprégnation progressive des transformations culturelles apportées par la Renaissance. Ainsi les nouvelles formes artistiques qui s'épanouissent au XVII ${ }^{\mathrm{e}}$ siècle participent à une reconfiguration des croyances, ou du moins entrent pour une part en symbiose avec les formes de spiritualité alors promues par l'Église post-tridentine.

Un point d'observation privilégié pour étudier ces zones de convergence ou d'interférence est celui des pratiques artistiques et religieuses accompagnant le culte des images miraculeuses à travers la catholicité du XVII ${ }^{\mathrm{e}}$ siècle. C'est à ce moment que l'Église de la Contre-Réforme cherche à donner un nouveau souffle à ces pratiques qui avaient été prises pour cibles par les protestants au siècle précédent et qui restent un des principaux - ou tout au moins un des plus visibles - points de fracture continuant à opposer les confessions adverses. Parmi les figures ainsi religieusement promues et artistiquement exaltées, une place de choix fut réservée à la Vierge. Figure conquérante de la Contre-Réforme, elle est 
invoquée, principalement dans les monarchies habsbourgeoises, comme protectrice du territoire et garante du pouvoir. Figure hautement identitaire à l'échelle de la catholicité et à celle des États, elle joue également le rôle de ciment communautaire à des niveaux plus locaux. Ainsi naissent ou renaissent, sous l'impulsion des princes mais aussi du clergé local comme des confréries et des ordres religieux, de nombreux sanctuaires mariaux au cœur desquels se situent de modestes statues de la Vierge fortement attachées aux lieux de leur invention et qui deviennent à ce titre un repère bien tangible de l'identité croyante. Pour les principales d'entre elles, ce sont également de puissants aimants attirant des foules de pèlerins. Elles font dès lors l'objet de véritables stratégies de propagation sous forme de répliques, d'images dérivées et d'une littérature prosélyte. Elles constituent à ce titre des maillons essentiels dans une topographie de lieux sacrés dont on commence alors à dresser l'inventaire pour insister sur l'importance de ce maillage et de cette dissémination de la piété mariale.

Étudier les multiples facettes des images sacrées de cette figure ubiquitaire permet donc d'envisager l'articulation entre différents niveaux de pouvoir et différentes formes de croyance. Mais force est de constater que si l'instrumentalisation politico-religieuse et la place centrale du culte marial dans les pratiques dévotionnelles ont déjà fait l'objet de plusieurs études ${ }^{1}$, une attention moindre a été portée aux images qui se trouvent au cœur de ces pratiques. Certes, un intérêt renouvelé s'est marqué, ces dernières années, pour le pouvoir des images cultuelles au premier âge moderne, replacées dans un contexte de débats autour du statut, des fonctions

1. On peut se contenter de citer ici, parmi les nombreuses études récentes sur ce sujet, les références suivantes: Annick Delfosse, La «Protectrice du PaïsBas». Stratégies politiques et figures de la Vierge dans les Pays-Bas espagnols, Turnhout, Brepols, 2009; Bruno Maes, Le Roi, la Vierge et la nation. Pèlerinages et identité nationale entre Guerre de cent ans et Révolution, Paris, Publisud, 2002; Bridget Heal, The Cult of the Virgin Mary in Early Modern Germany. Protestant and Catholic Piety 1500-1648, Cambridge, Cambridge University Press, 2007, Gary Waller, The Virgin Mary in Late Medieval and Early Modern English Literature and Popular Culture, Cambridge, Cambridge University Press, 2011. Il convient également d'accorder une place particulière à la parution récente d'un important travail d'équipe consacré à l'Atlas Marianus de W. Gumppenberg: Olivier Christin, Fabrice Flückiger et Naïma Ghermani (dir.), Marie mondialisée. L'Atlas Marianus de Wilhelm Gumppenberg et les topographies sacrées de l'époque moderne, Neuchâtel, Alphil, 2014. 
et des usages de l'image, comme dans le cadre des croyances qui leur donnèrent sens et existence ${ }^{2}$. Si ces travaux participent d'un certain tournant anthropologique dans le champ de l'histoire comme de l'histoire de l'art - avec un intérêt marqué pour les modalités de réception, autres qu'exclusivement esthétique, de l'art et des images -, il apparaît que les tentatives d'articulation entre les dimensions formelles, matérielles, spatiales, symboliques, cultuelles... ne sont pas nombreuses.

Les présentes contributions, que l'on doit à des historiens comme à des historiens de l'art, cherchent précisément à restituer les enjeux religieux et culturels liés au culte des images miraculeuses de la Vierge appréhendées comme objets aux caractéristiques spécifiques et comme phénomènes intégrés dans un cadre rituel et symbolique particulier. En portant l'attention sur ces images et sur la littérature comme sur l'iconographie qu'elles ont pu générer, ce numéro thématique contribue à une meilleure connaissance de la place centrale qu'elles ont pu occuper dans les pratiques religieuses et les systèmes de croyance au premier âge moderne ${ }^{3}$.

ralph.dekoninck@uclouvain.be

2. Voir entre autres David Freedberg, Le pouvoir des images, trad. fr. par Alix Girod, Paris, Gérard Monfort, 1998. Hans Belting, Image et culte. Une histoire de l'image avant l'époque de l'art, trad. fr. Frank Muller, Paris, Cerf, 1998. Olivier Christin, Une révolution symbolique. L'iconoclasme huguenot et la reconstruction catholique, Paris, Éditions de Minuit, 1991. Megan Holmes, The Miraculous Image in Renaissance Florence, New Haven - Londres, Yale University Press, 2013. Erik Thuno et Gerhard Wolf (éd.), The Miraculous Image in the Late Middle Ages and Renaissance, Rome, L'Erma di Bretschneider, 2004. Jane Garnett et Gervase Rosser, Spectacular Miracles. Transforming Images in Italy, from the Renaissance to the Present, Londres, Reaktion Books, 2013. Felipe Pereda, Las imágenes de la discordia. Política y poética de la imagen sagrada en la España del 400', Madrid, Marcial Pons, 2007. Gerhard Wolf, Schleier und Spiegel, Traditionen des Christusbildes und die Bildkonzepte der Renaissance, Munich, Wilhelm Fink, 2002.

3. Ce numéro est le fruit d'une journée d'études organisée à l'Université de Louvain en mars 2012 par Ralph Dekoninck et Silvia Mostaccio dans le cadre du Groupe d'analyse culturelle de la première modernité (GEMCA). 